\title{
Farming in a subtropical environment: a farmer's perspective
}

\author{
M. JAGGER \\ Dairy farmer, Whangarei Heads \\ murrayjagger@clear.net.nz
}

I am the fifth generation on the family's coastal farm at Whangarei Heads, east of Whangarei, where I have farmed for 25 years. It is predominantly a dairy farm with an associated dairy beef operation. The farm carries 560 Jersey dairy cows plus replacements and 250 Angus-Jersey cross cattle, sourced primarily from the dairy herd. The farm has a flat to rolling contour on three main soils: Rangiuru clay, Waipu clay and Waipu peaty loam, with some recently purchased sand country.

Annual rainfall is variable (650 to $1200 \mathrm{~mm}$ ) averaging $800 \mathrm{~mm}$. Rainfall tends to be mostly between July and September and the area tends to be summer dry. Frosts are infrequent and light during winter. However, there is the odd year when frosts can suppress kikuyu growth. Ground temperature ranges from $8^{\circ} \mathrm{C}$ in winter to $22^{\circ} \mathrm{C}$ in summer.

Pasture is predominantly kikuyu (Pennisitum clandestinum)-dominant with $10-12 \%$ of the dairy unit in perennial (Lolium perenne) ryegrass and white clover (Trifolium repens) pastures. About 60 ha or 33\% of the dairy farm is also direct-drilled with modern Italian ryegrasses (Lolium multiflorum) each year and a further $8 \%$ or 16 ha is summer cropped allowing renewal of the poorer performing pastures. The ryegrass/white clover pastures usually start to revert back to kikuyu after their second summer because dry summers favour kikuyu over ryegrass. Kikuyu seed stays viable in the ground for at least 7 years so complete exclusion is almost impossible.

There is no doubt that pockets of Northland have different pasture growth patterns that are matched in other parts of Northland and the North Island that have seen changes in the last 30 years, and particularly the last 10 years, with the spread of plants like kikuyu that thrive in a subtropical environment. In 1974, kikuyu grass was estimated to cover over $10 \%$ of Northland farmland (Piggot 1985), and was present in other coastal areas throughout the North Island, and by 1985 that area had doubled, with a small presence in a greater area of farmland. The prediction in 1985 was that by 2000 , kikuyu would be the primary pasture grass in Northland. The assumption of 5\% spread per decade has been proven correct. In 1990, kikuyu was found to be present on $71 \%$ of dairy farms and $61 \%$ of sheep and beef farms (Woods \& Andrewes 1990).

So has this rapid spread of kikuyu been because our climate has become more subtropical or has the kikuyu plant evolved to suit the environment and just become more dominant? My view is both are true. We certainly have seen weather patterns in the last 10 years that suit the growth of kikuyu. Our recent summers and autumns have been wetter on average than previously, and our winters have been milder. Our farm management has also developed with improved fertility and a greater use of nitrogen, which again has suited kikuyu. Both these factors have contributed to the plants progression throughout Northland farmland. The structure and chemical composition of kikuyu plant has evolved to suit our farming practices. On well managed farms kikuyu is no longer the coarse, hairy unpalatable plant it once was. There is evidence (Marais 2001) that kikuyu has developed structures and mechanisms which impede predation. The nutritive quality of kikuyu varies during the milking season which is evident particularly during the autumn when the morphology, physiology and chemical composition can vary to greater or lesser extent, according to the growth stage and environmental conditions experienced (Reeves 1997). There is no doubt that after farming kikuyu for 25 years there is evidence of these changes by the plant, which in turn, affects milk production, animal growth rates, pasture establishment and plant quality.

Mechanical control, direct-drilling of Italian ryegrass, improved pasture management practices and supplementation of the animal to counteract feed deficits, are tools I have used effectively on my farm for over 20 years. But these alone are not the complete answer. I question whether following current management practices, developed for temperate species, are optimum for kikuyu. If we wish to optimise productivity and animal production from kikuyu pastures we need to understand how they perform, what is the most appropriate way of counteracting the imbalances kikuyu is creating, and what is an ideal feed source to supplement dairy cows given kikuyu's composition? Again, current concepts have been developed for a temperate pasture environment.

There has been some very good research undertaken in Northland on kikuyu over the years to help farmers understand the plant, its growth patterns and appropriate farm management techniques. Despite all this work, there are still some unanswered questions relating to pasture productivity improvement, such as monthly changes on a well managed kikuyu pasture and a ryegrass pasture in the same environment. 
I initiated a project where three cages (each $3 \times 1.5$ $\mathrm{m})$ were set up on a ryegrass-dominant and also a seasonably-dominant kikuyu paddock. These cages were measured monthly and results recorded over 2 years. At the same time grab samples were hand-cut on transects across 4 paddocks ahead of the cows to compare what they were actually grazing as opposed to the ungrazed cage environment. A yield measurement by the standard MAF technique of mowing was used. Mown pasture was weighed and a sub-sample taken and dried overnight in a forced-draft oven before being analysed by NZ LABs for nutritional variables like metabolisable energy content. The caged pasture was pre-trimmed and shifted to a fresh site in the paddock after each cut. The hand-cut pasture samples were dried and a nutritional analysis undertaken by NZ LABs. The information obtained is presented below.

\section{Pasture growth}

Cumulative growth (Fig. 1) over Year 1 (October 2005September 2006) varied considerably from that grown in Year 2 (October 2006-August 2007). Year 1 data showed the ryegrass pasture grew 3\% more dry matter than the kikuyu, but in Year 2 (dry summer) it grew $41 \%$ less pasture than in Year 1, while the kikuyu grew only $7 \%$ less pasture than in Year 1.

This demonstrates the value of kikuyu in years with dry summers, provided it is well managed.

\section{Pasture energy}

There was a large difference in energy produced between the two pastures in Year 1, with the ryegrass pasture producing $10 \%$ more energy whilst only growing 3\% more grass.

Year 1 average kikuyu ME content was 10.6 MJ ME/ $\mathrm{kg}$ DM compared with 11.4 MJ ME/kg DM for ryegrass. In Year 2 the kikuyu pasture grew 34\% more energy than the ryegrass pasture. The average kikuyu ME content was $10.8 \mathrm{MJ}$ ME / kg DM compared with 11.9
MJ ME/kg DM for ryegrass. Whilst the overall pasture and ME production over 2 years shows interesting results we need to put this in perspective with energy density by harvest.

\section{Energy density}

The ryegrass pasture had a consistently higher energy density compared with the kikuyu pasture in the first year, 10.5 MJ ME/kg DM being the critical level for milk production and liveweight gain in cattle. Year 1 kikuyu pasture was below $10.5 \mathrm{MJ} \mathrm{ME} / \mathrm{kgDM}$ for most of the late summer and autumn, while ryegrass pasture dropped for a much shorter period. Regardless of growth rate the kikuyu pasture has difficulty providing sufficient energy for high milk production and livewieght gain during March and April.

In Year 2, dry conditions from December to April reduced pasture growth by up to $41 \%$. Ryegrass pastures are far more susceptible to dry conditions than are those kikuyu-based. The ryegrass cages were unable to grow enough pasture to sample during March and April in Year 2, and although ryegrass pastures had a higher energy content than kikuyu pastures in that year this was insufficient to offset lost pasture production because of the dry conditions.

\section{Pasture quality}

During the 2 year trial the kikuyu pasture flourished while the ryegrass pasture did not.

Kikuyu made up between $17-20 \%$ of pasture growth during spring months and $90 \%$ during autumn, and clover content was low at $4 \%$ of DM. Kikuyu growth must be controlled to reduce losses in pasture quality. The ryegrass pastures always had more white clover ( $10 \%$ over Year 1 and $40 \%$ over Year 2$)$. The stress put on the ryegrass pasture during the prolonged dry spell in Year 2 reduced pasture production over the following winter, and allowed kikuyu to invade at a faster rate.

Figure 2 Crude protein (\% of DM) in kikuyu and ryegrass pastures over 2 years (October 2005 - August 2007). tober 2005-September - August 2007).

Cumulative Growth Kikuyu \& Ryegrass 2005-07

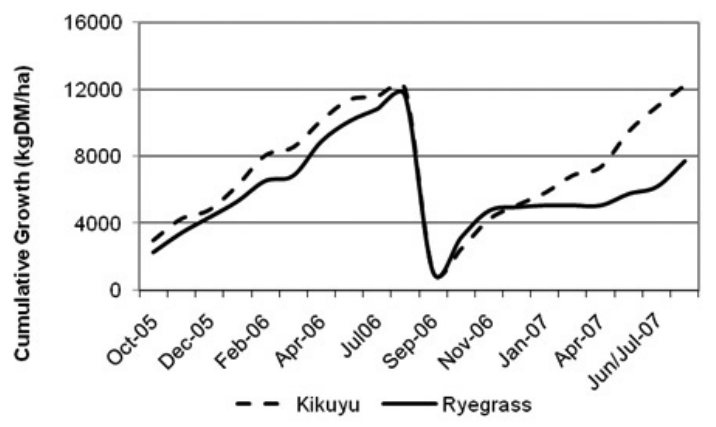

\section{Crude Protein: Kikuyu \& Ryegrass}

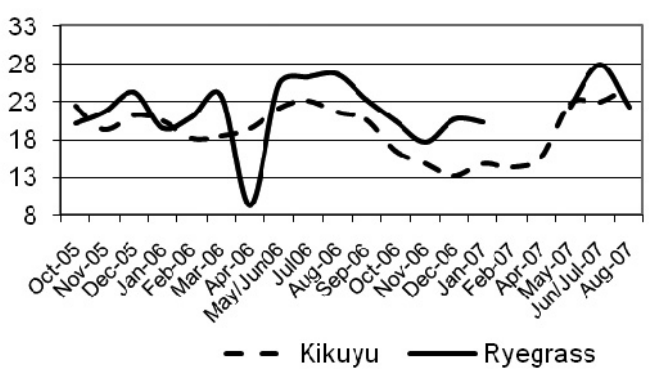




\section{Project conclusion}

The project provided some valuable insights and learning. Those of us who have been farming a subtropical plant like kikuyu for some time have developed and refined management techniques to extract the best from it. There is no doubt that a kikuyu-dominant pasture can match dry matter production during the milking season with that from a ryegrass-dominant pasture, but it can not do this consistently. The growth pattern of kikuyu does not always match the production pattern of our farming systems. The project results clearly identify why we use vigorously establishing Italian ryegrasses and white clover to balance the pasture supply of ME.

The fact that one out of the 2 years of the project was drier than normal highlights the environment that kikuyu, a deep rooting plant, thrives in and helps us understand why it has spread around Northland and beyond. Kikuyu offers a great opportunity to capture improved productivity and profitability because it can consistently outperform ryegrass in dry matter production. What we need to do now is to counter the plant's nutritive deficiencies using supplements. If supplements are to counter deficiencies in kikuyu herbage then this must be associated with pasture management that minimises pasture substitution.

Kikuyu is a natrophobe and is incapable of providing enough sodium for grazing animals even when the soil contains sufficient sodium; animals grazing kikuyudominant pastures should be supplemented with sodium (Smith 1981). This problem is exacerbated if kikuyu is grazed when past the five leaf stage.

Crude protein (Reeves et al. 1996) levels in the kikuyu pasture also decline as the pasture goes past the five leaf stage, reducing milk yields and cattle liveweight gain. Research indicates that grazing the kikuyu plant at a particular leaf stage as opposed to a particular rotation length, is beneficial.

Kikuyu pastures also contain oxalic acid that reduces calcium availability to the cow (Marias 2001) and sometimes causes acute toxicity.

Farmers have to grapple with some of the issues outlined above, especially in autumn, when growth rates on kikuyu pastures exceed cow requirements. Pasture quality declines rapidly along with production as cows become lethargic and some get cloudy eyes along with an increase in somatic cell count. Livestock do not put on weight and introduced ryegrass struggles to compete with kikuyu.

In general terms, farming is one of the few businesses where the primary resource (pasture) is not clearly understood. There are more farmers now than there were 10 years ago measuring and monitoring the quality and quantity of the pasture that goes into their animals, but generally we rely on information previously collected or what we have traditionally done, with most advice based on temperate pasture species. So as subtropical plants like kikuyu evolve and spread we need to have a greater understanding of the implications and how the plant interacts with the animal.

Having reviewed the data collected on our farm we can make some assumptions. There is no substitute for energy. Kikuyu has inconsistent energy levels which are exasperated by poor management. Ensuring that we strive to keep the pastures at optimum energy levels is paramount and then adding energy at strategic times becomes economic. With a better understanding of the plant, and especially what effect ageing of the plant has on its performance, we can then make better management decision.

For example, if we look at our farm crude protein levels over 2 years (Fig. 2) we can identify the periods of deficiency. Although generally not limiting, the kikuyu pastures are lowest in crude protein concentration during summer and autumn, the period of pasture dominance and highest NDF and lowest energy. Feeding high ME supplements (Bryant \& McLeod 2007) is beneficial, with turnips and palm kernel appearing to be the most suitable. If crude protein levels are lower than we achieved in Year 2 (dry year) then feeding turnips and maize would be unsuitable as protein levels in the diet would border on being deficient. In this case, palm kernel or grass silage would be more appropriate.

\section{Where to next}

My thoughts are that we know a great deal about growth patterns and ME levels in kikuyu, and we have developed some very good tools for managing the plant, but we do not know enough about interactions with other plants and stock, particularly in the autumn. Kikuyu is becoming more dominant and is adapting to our farming systems. It is time we invested in improving the plant as opposed to understanding it.

\section{Summary}

Whilst not deemed a true subtropical environment, climatic conditions over the last 3 decades have allowed subtropical species like kikuyu to spread at a land area rate in excess of $5 \%$ per decade. Through collective understanding we must take the opportunity to harness the potential advantages kikuyu has to improve onfarm productivity.

I have 25 years of farming kikuyu grass and have proven the importance of establishing Italian ryegrass into kikuyu in autumn to boost winter/spring production. Kikuyu has evolved to suit our farming environment and is no longer the unpalatable plant it once was. Kikuyu pastures are different to ryegrass pastures but all our management practices and growth curve 
information is based around temperate pasture species. Farmers need to realign management practices to suit kikuyu pastures. Kikuyu pasture should be grazed at the 4.5-5 leaf stage as opposed to 2.5-3 stage in a perennial ryegrass pasture.

Kikuyu pastures grow less than ryegrass pastures in the winter/spring season and more in the summer/ autumn. Kikuyu energy levels are lower than ryegrass pastures and this is most noticeable in autumn. Thus, kikuyu requires proactive management practices to ensure consistent productivity, and so clover and ryegrass can thrive. Relying on livestock to control kikuyu in the autumn will result in lower pasture growth rates and milk production.

My recent research indicates that autumn production would be improved by using a crop such as turnips or palm kernel, provided it is economic to do so. Supplementation while grazing kikuyu is beneficial but can lead to pasture substitution.

Kikuyu is a $\mathrm{C}_{4}$ grass. In $\mathrm{C}_{4}$ plants, carbon dioxide is first fixed into a compound containing four carbon atoms before entering the photosynthetic cycle. These plants are better adapted to high daytime temperatures, intense sunlight and drought than are temperate $\left(\mathrm{C}_{3}\right)$ species like perennial ryegrass. Kikuyu is a natrophobe. Natrophobes are incapable of absorbing sufficient sodium to satisfy grazing animals.

I would like to finish by quoting a statement made by J.P. Marais, Natal Department of Agriculture Proceedings: Kikuyu Technology Day p.6, 1999.

"With the exception of high nitrate levels, none of the known anti-quality factors in kikuyu can be eliminated by good farm management practices. Inadequate amounts of readily available energy, sodium and calcium in the diet of animals on kikuyu, can be corrected by supplementation. However, more attention should be given to the study of kikuyu ecotypes having more favorable chemical compositions."

\section{ACKNOWLEDGEMENTS}

The project was jointly funded by the Meat and Wool NZ FITT fund through the Northland Kikuyu Action Group (KAG).

\section{REFERENCES}

Bryant, J.R.; Mcleod, K.L.M. 2007. AgResearch External Report. Supplementary feed options for kikuyu pastures.

Marais, J.P. 2001. Factors affecting the nutritive value of kikuyu grass. Tropical Grasslands 35: 65-84.

Piggot, G.J. 1985. Kikuyu grass farming for high production. Published by Northland Pasture. 3 pp.

Reeves, M. 1997. Milk production from kikuyu grass pasture. PhD thesis, University of Sydney.

Reeves, M.; Fulkerson, W. J.; Kellaway, R.C. 1996. Forage quality of kikuyu: The effect of time of defoliation and nitrogen fertilizer application and in comparison with perennial ryegrass. Australian Journal of Agricultural Research 47: 1349-1359.

Smith, G. 1981. Sodium requirements of farm livestock. New Zealand Journal of Agriculture 142: 21-25.

Wood, P.W.; Andrewes, W.G.K. 1990. Final report to the Ministry for the Environment. New Zealand Climate Change Programme. 